\title{
Community partnerships fill mental health gaps
}

$\mathrm{P}$ olice, hospitals and community health services across Canada are launching innovative partnerships to improve information-sharing and coordination to address gaps in the mental health system.

The impetus for change arose out of police encountering more people in acute psychiatric distress and wasting resources in having to escort patients to emergency departments, a widespread practice. Not only do police have to spend hours in emergency rooms, hospital resources are often unnecessarily spent on patients who could be treated in the community.

Also, being taken to a hospital "in the back of a cruiser" is stigmatizing and demoralizing for patients, explains Claude Anderson, executive director for Canadian Mental Health Association's branch in Grey and Bruce counties in Ontario.

In August, the Grey Bruce branch launched an "urgent response team," which includes six full-time mental health workers and operates 12 hours a day, 7 days a week, with a target response time of under an hour. The team reduces emergency department visits by "reconnecting patients with services in the community" or encouraging patients to restart their medications, says Anderson.

Since 2012, three Assertive Community Treatment teams - which include police, psychiatrists, nurses and addiction counsellors - have been launched in Vancouver, British Columbia. If a patient misses appointments, officers can be notified, check if the person is in custody and arrange for treatment.

Also, because police officers often see patients in the community, they can alert health services if someone's condition appears to be worsening before the situation comes to a head. The Vancouver Police Department is calling for seven more teams.

The teams "have reduced rehospitalization by at least $50 \%$," says John Higenbottam, cochair of the Canadian

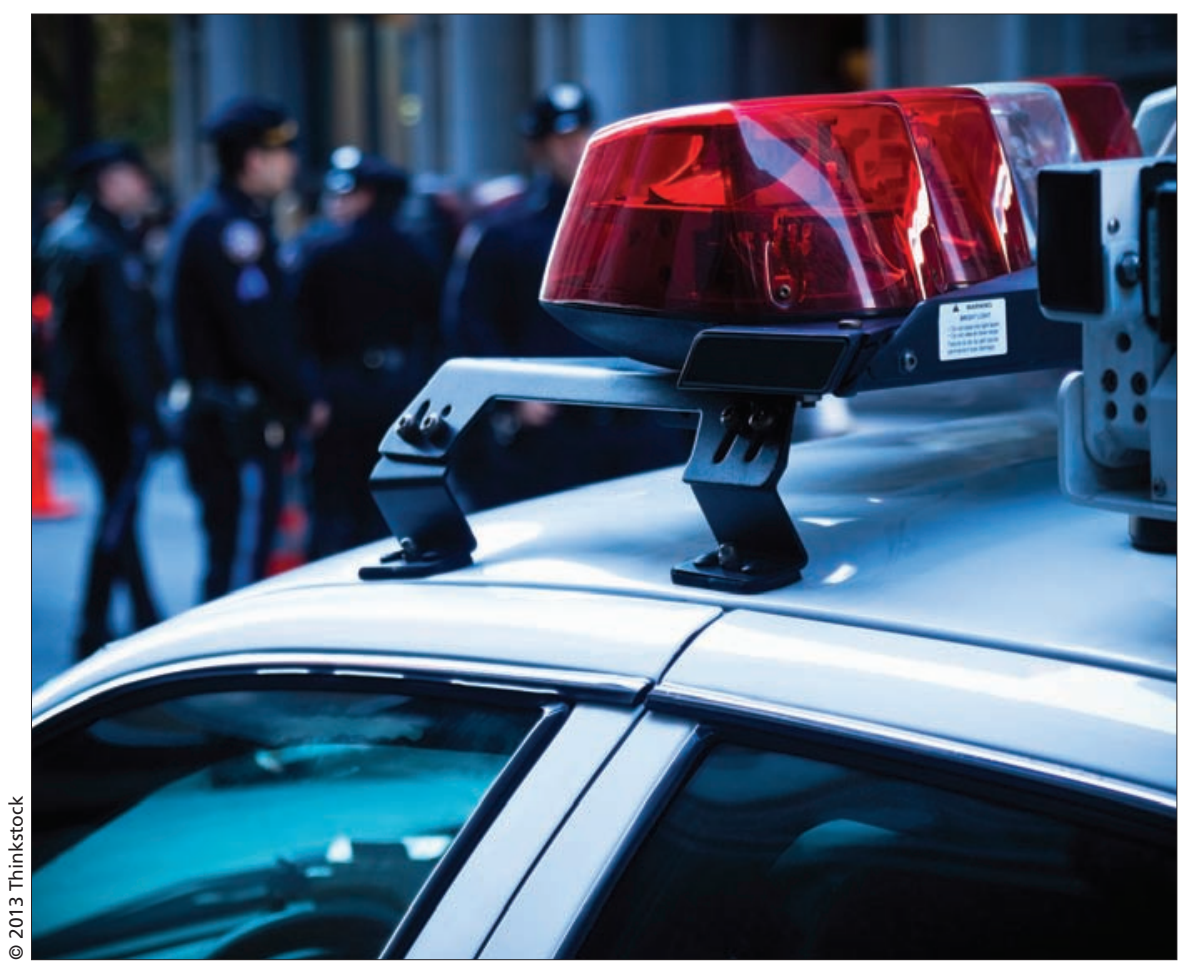

It can be stigmatizing and demoralizing for people under acute psychiatric distress to be carried to the hospital in a police cruiser, say mental health experts.

Alliance on Mental Illness and Mental Health.

The Crisis Outreach And Support Team (COAST) in Hamilton, Ontario, takes a similar approach, coordinating St. Joseph's Healthcare, Hamilton Police Services and community services. Members of the public, police officers and health workers can ask a team, consisting of a nurse and a police officer, to visit patients in the community on a routine or emergency basis.

"The officers are in plain clothes, and that reduces the stigma of mental illness," said Sarah Burtenshaw, a trainer with the program.

"If we have someone in the emergency room that has left and we're concerned about them, we can use COAST as a means to check on them," says Jodi Younger, operational service manager of general psychiatry and addiction at St. Joseph's.

By bringing police and health personnel under one roof, these teams overcome the information-sharing challenges that continue to hamper integrated care in most of Canada.

In Saskatchewan, for example, Clive Weighill, chief of Saskatoon Police Services explains, "We have the Health Information Protection Act, which prevents health information from being shared, and then we have the Police Act, which prevents the police from sharing information. ... We have to do things with a wink and a nudge, and we don't like to operate like that."

Dr. Kwame McKenzie, a medical director at the Centre for Addiction and Mental Health in Toronto, Ontario, argues that although the partnerships and initiatives are helpful, a major transformation of the mental health system is what's needed.

He thinks Canadian mental health services should be modelled after those in the United Kingdom, where a GP or doctor representing a group of GP offices are on call $24 / 7$ and serve as the 
main point of contact when a person is in distress.

The doctor "would make a risk assessment and discuss the case with mental health workers," says McKenzie, who explains the system reduces police arrests because mental health workers feel confident intervening in streets and homes when they know a person's psychiatric history.
In Canada, by contrast, primary care providers sometimes don't receive word that a patient has been admitted to hospital until after they've been discharged, explains Higenbottam.

Given a highly fragmented mental health system and poor continuity of care, police officers lament that the burden of linking patients to care is too often left to them.
"A mental health crisis is the only medical emergency I know of where the first responder is not a medical professional," says Anderson. "When I talk to a police officer, the first thing I do is apologize to them on behalf of the mental health services for not doing our job." - Wendy Glauser, Toronto, Ont.

CMAJ 2013. DOI:10.1503/cmaj.109-4616 